\title{
KEMATANGAN MOLEKULER FRAKSI HIDROKARBON AROMATIK CORE BADAK 1/208 MUARA BADAK, KUTAI KARTANEGARA, KALIMANTAN TIMUR: SUATU TINJAUAN KUALITATIF
}

\section{R. Arizal Firmansyah ${ }^{1}$ dan R.Y. Perry Burhan ${ }^{2}$}

\begin{abstract}
ABSTRAK
Kajian kualitatif tentang kematangan termal biomarka fraksi hidrokarbon aromatik pada core Badak 1/208 dari kedalaman 10550 kaki telah dilakukan untuk meminimalisir resiko kegagalan kegiatan eksplorasi minyak di sumur Badak 1/208 Muara Badak, Kutai Kartanegara-Kalimantan Timur. Sampel core diekstraksi secara berselang seling dengan campuran pelarut toluena-metanol (3:1) dan kloroform-metanol (3:1), kemudian difraksinasi dengan metode kromatografi kolom untuk memperoleh fraksi netral, asam, dan polar. Fraksi netral yang diperoleh difraksinasi lebih lanjut dengan kromatografi lapis tipis menghasilkan fraksi hidrokarbon alifatik, aromatik, alkohol, dan keton. Fraksi hidrokarbon aromatik yang diperoleh, selanjutnya diidentifikasi menggunakan Kromatografi Gas-Spektrometer Massa (KG-SM) dengan hasil antara lain turunan pisena, alkil fenantrena, dan triaromatik steroid. Biomarka fraksi hidrokarbon aromatik yang teridentifikasi tersebut ditinjau dari pembentukannya selama waktu geologi, menunjukkan bahwa core yang ada diduga matang secara termal.
\end{abstract}

Kata kunci: biomarka, hidrokarbon aromatik, core, Badak

\footnotetext{
${ }_{1}$ Dosen Tadris Kimia Fakultas Tarbiyah IAIN Walisongo Semarang

${ }^{2}$ Dosen Kimia FMIPA Institut Teknologi Sepuluh Nopember Surabaya
} 


\section{LATAR BELAKANG}

Minyak bumi hingga saat ini masih merupakan sumber energi utama. Hal ini dapat diketahui dari terus meningkatnya permintaan dunia terhadap minyak bumi, begitu pula halnya dengan negara Indonesia. Adanya peningkatan permintaan minyak bumi khususnya di Indonesia ini harus diimbangi dengan peningkatan produksi. Bila tidak, krisis energi akan menjadi ancaman serius.

Terkait dengan produksi minyak bumi di Indonesia, dari tahun ke tahun mengalami penurunan. Banyak faktor yang menjadi penurunan produksi minyak bumi, diantaranya adalah lapangan minyak yang sudah tua, kurang memperhatikan sumber-sumber minyak marjinal. Padahal peran sumber-sumber minyak marjinal tidak dapat dianggap remeh. Adanya sumbersumber minyak marjinal yang banyak, bila dieksploitasi secara optimal tidak akan diragukan lagi akan menambah produksi minyak. Oleh karena itu, upaya mencari lapangan minyak baru (termasuk di dalamnya sumber minyak marjinal) atau blok-blok baru dapat membantu untuk meningkatkan produksi minyak bumi di Indonesia.

Dalam mencari atau eksplorasi sumber-sumber minyak baru tersebut, perlu banyak hal yang harus diperhatikan agar memberikan hasil yang signifikan atau paling tidak resiko kegagalan tidak ditemukannya minyak dapat diminimalisir. Salah satunya adalah memanfaatkan data geokimia organik sebagai hasil dari pengkajian biomarka ${ }^{3}$ (fosil molekul) yang terdapat dalam batuan induk (core), sampel minyak bumi atau sampel geologi lainnya.

Peranan data geokimia organik dalam eksplorasi sumbersumber minyak dapat diketahui melalui informasi tentang korelasi minyak-batuan induk (core) atau korelasi minyak-minyak.

\footnotetext{
${ }^{3}$ Biomarka adalah bahan organik yang terpendam selama periode waktu geologi tertentu yang mengalami degradasi dan perubahan gugus fungsi namun kerangka asalnya masih tetap sehingga memungkinkan untuk ditelusuri lebih lanjut prekursornya (Killops dan Killops, 1999).
}

70 Jurnal PHENOMENON, Volume 2 Nomor 1, November 2011 
Korelasi minyak-batuan induk memiliki prinsip dasar bahwa komposisi senyawa-senyawa organik yang terdapat dalam suatu batuan induk akan ditransmisikan ke dalam minyak. Jika diketahui komposisi senyawa-senyawa organik dalam suatu sampel minyak sama dengan yang terdapat pada ekstrak suatu batuan induk, maka sampel minyak tersebut diduga kuat berasal dari batuan induk tersebut. Hal ini akan mempermudah dalam memastikan batuan induk manakah yang menghasilkan minyak dari beberapa batuan induk yang ada (Cole et al., 1995). Peranan data geokimia organik lainnya dapat diketahui dari informasi kematangan molekuler dalam core. Kematangan molekuler adalah ukuran seberapa jauh reaksi yang disebabkan panas untuk mengkonversi materi organik sedimenter menjadi petroleum (struktur senyawa hidrokarbon yang terkandung di dalamnya juga berubah menjadi struktur senyawa yang lebih stabil), misalnya kerogen (dalam core) dapat dikonversi secara termal menjadi minyak dan gas yang selanjutnya akan bermigrasi ke batuan reservoir. Dengan demikian dapat dikatakan bahwa senyawa hidrokarbon yang terdapat di dalam minyak lebih stabil secara termal daripada prekursornya (senyawa hidrokarbon dalam kerogen) (Manggo, 1991).

Kematangan molekuler suatu core atau sampel geologi lainnya dapat diketahui dengan berbagai macam indikator atau parameter, salah satunya dengan memanfaatkan hasil kajian biomarka yang dikenal dengan parameter kematangan biomarka (biomarker maturity parameter) (Peters dan Moldowan,1993). Parameter ini didasarkan pada konfigurasi isomer, aromatisasi, kelimpahan hidrokarbon rantai pendek dan proses cracking (Killops dan Killops, 1993). Berdasarkan parameter ini, kandungan biomarka (baik secara kualitatif maupun kuantitatif) yang menjadi indikator kematangan dalam sampel geologi dapat memberikan informasi matang tidaknya sampel tersebut sehingga menjadi bahan pertimbangan layak tidaknya dilakukan eksploitasi minyak selama kegiatan eksplorasi minyak berlangsung. Hal ini dapat diketahui dari penelitian sampel sedimen yang diambil dari sumur minyak 1 Merkuri, berlokasi di dataran tinggi Ex- 
mouth Australia Barat (Larcher, 1987) yang memberikan informasi bahwa dari fraksi alifatik atau alkana, sedimen yang lebih matang mengandung moretana dengan konfigurasi 22S, sedangkan konfigurasi 22R lebih banyak terdapat dalam sedimen yang belum matang.

Berdasarkan peranan data geokimia organik tersebut terutama tentang kematangan molekuler core yang dapat membantu meminimalisir kegagalan dalam eksplorasi minyak bumi, maka artikel ini mengangkat masalah kematangan molekuler fraksi hirokarbon aromatik hasil ekstrak sampel core yang diambil dari kedalaman 10550 kaki di sumur Badak 1/208 Muara Badak, kutai Kartanegara Kalimantan Timur oleh Virginia Indonesia Company (VICO) ${ }^{4}$.

\section{TUJUAN}

Penelitian ini bertujuan untuk mengetahui secara kualitatif apakah sampel core yang diambil dari kedalaman 10550 kaki di sumur Badak 1/208 Muara Badak, Kutai Kartanegara Kalimantan Timur matang atau tidak.

\section{MANFAAT PENELITIAN}

Hasil penelitian ini harapannya dapat membantu memberikan deskripsi singkat secara kualitatif mengenai kematangan molekuler sampel core dari kedalaman 10550 kaki hasil kegiatan eksplorasi minyak yang dilakukan oleh VICO di sumur Badak 1/208 Muara Badak, Kutai Kartanegara Kalimantan Timur.

\section{METODE PENELITIAN}

Metode yang digunakan dalam penelitian ini mengadopsi metode McCarthy dan Duthie (1962). Sampel core diekstraksi secara berselang seling dengan campuran pelarut toluena-metanol (3:1) dan kloroform-metanol (3:1). Kemudian difraksinasi den-

\footnotetext{
${ }^{4}$ Merupakan salah satu perusahaan Kontraktor Kontrak Kerja Sama (KKKS) ditunjuk BPMIGAS untuk melakukan proses pengeboran minyak dan gas bumi.
} 
gan metode kromatografi kolom untuk memperoleh fraksi netral, asam, dan polar. Fraksi netral yang diperoleh difraksinasi lebih lanjut dengan kromatografi lapis tipis menghasilkan fraksi hidrokarbon alifatik, aromatik, alkohol, dan keton. Fraksi hidrokarbon aromatik yang diperoleh diidentifikasi menggunakan Kromatografi Gas-Spektrometer Massa (KG-SM).

\section{HASIL DAN PEMBAHASAN}

Biomarka fraksi hidrokarbon aromatik yang berhasil diidentifikasi adalah turunan pisena, alkil fenantrena, dan triaromatik steroid. Berikut pembahasan masing-masing biomarka tersebut.

\section{Turunan pisena}

Turunan pisena berhasil teridentifikasi pada sampel core melalui fragmentogram m/z 342 dan $m / z 324$ (Gambar 1 dan 2) dengan spektrum massa pada Gambar 3 dan 4 .

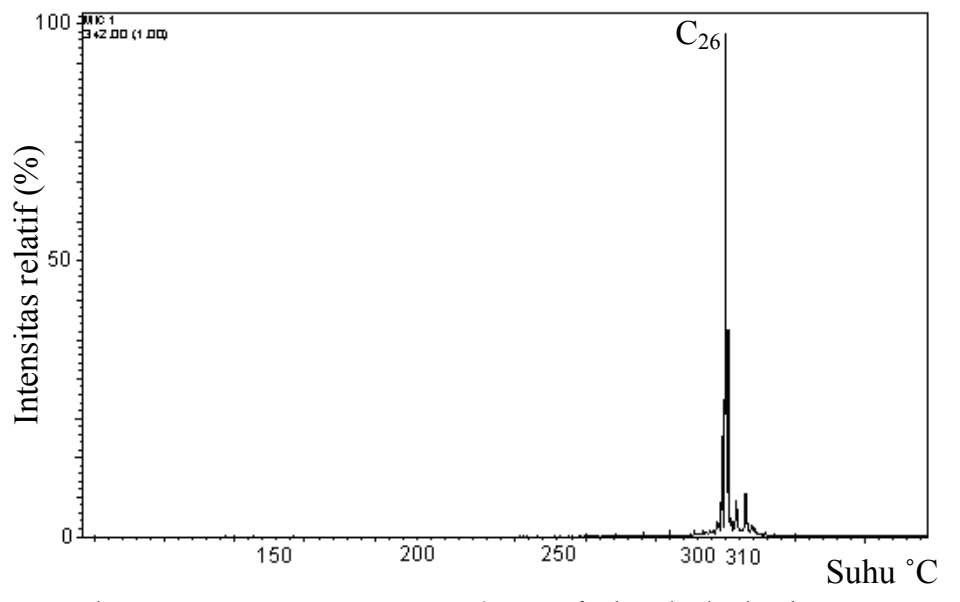

Gambar 1. Fragmentogram $m / z 342$ fraksi hidrokarbon aromatik sampel core. Program temperatur oven $100^{\circ} \mathrm{C}(5$ menit), $100-310^{\circ} \mathrm{C}\left(10^{\circ} \mathrm{C} /\right.$ menit $)$, isotermal $310{ }^{\circ} \mathrm{C}$ selama 10 menit. 
R. Arizal Firmansyah dan R.Y. Perry Burhan

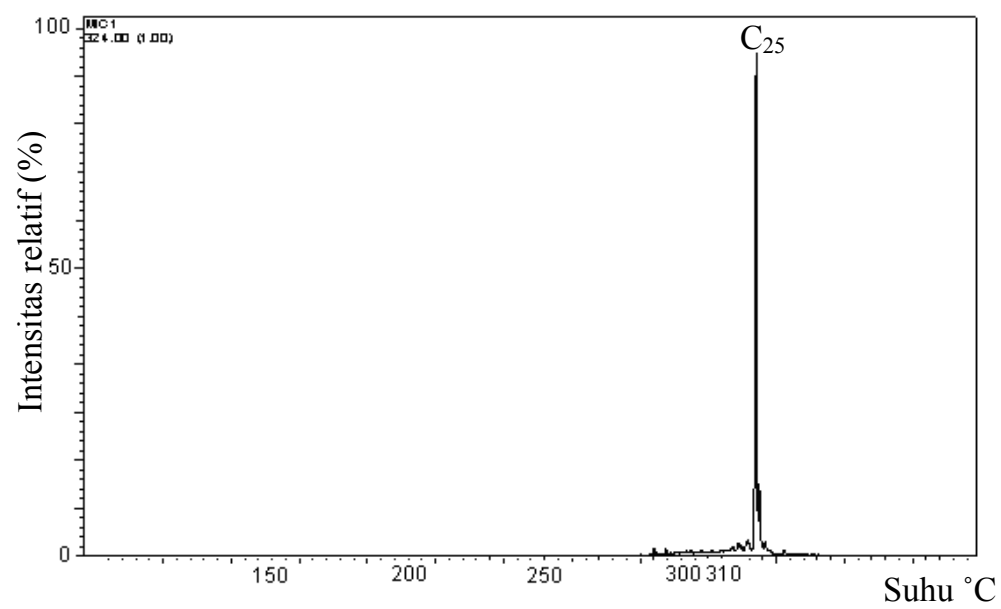

Gambar 2. Fragmentogram $m / z 324$ fraksi hidrokarbon aromatik sampel core. Program temperatur oven $100^{\circ} \mathrm{C}(5$ menit), $100-310^{\circ} \mathrm{C}\left(10^{\circ} \mathrm{C} /\right.$ menit $)$, isotermal $310{ }^{\circ} \mathrm{C}$ selama 10 menit.

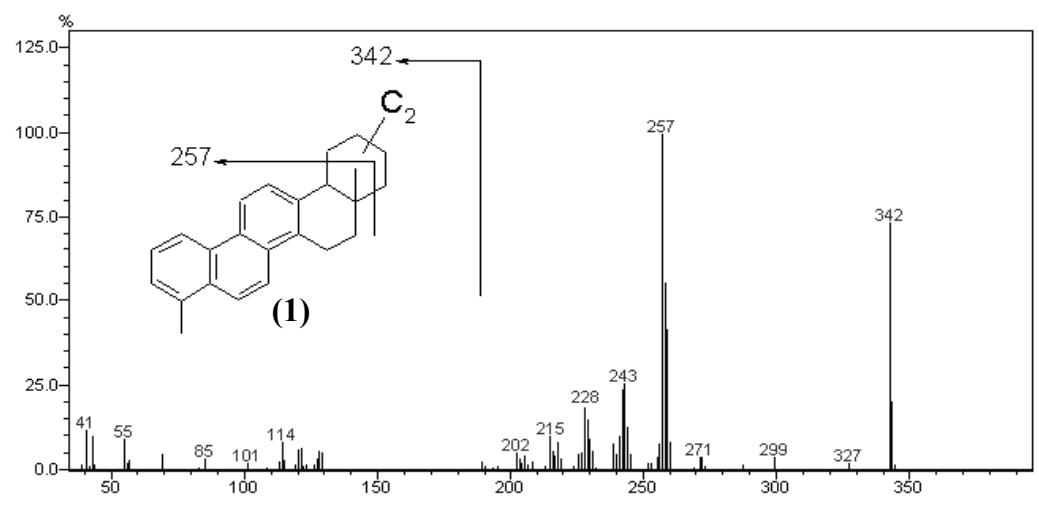

Gambar 3. Spektrum massa puncak ke-1dari fragmentogram $m / z$ 342 


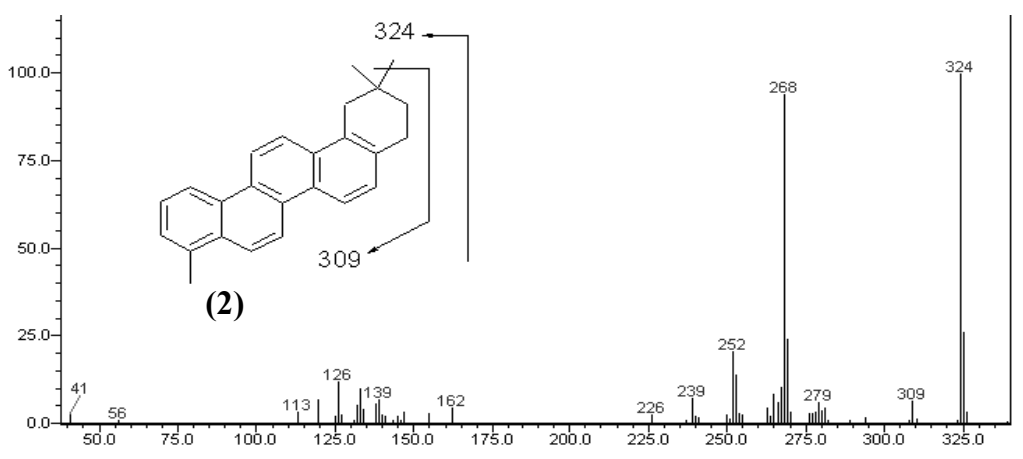

Gambar 4. Spektrum massa puncak ke-1dari fragmentogram $m / z$ 324

Fragmen ion utama $\mathrm{m} / \mathrm{z} 342$ dan 257 (puncak dasar); $m / z$ 324 dan 268 merupakan fragmen ion khas senyawa turunan pisena (Chaffee dan Fookes, 1988). Ion molekuler teramati pada m/z 342 (Gambar 3) menunjukkan bahwa senyawa yang dimaksud mempunyai derajat ketidakjenuhan 12, terdiri dari 7 ikatan rangkap dan 5 cincin. Sedangkan pada Gambar 4, ion molekuler teramati pada $\mathrm{m} / \mathrm{z} 324$ menunjukkan bahwa senyawa yang dimaksud mempunyai derajat ketidakjenuhan 14, terdiri dari 9 ikatan rangkap dan 5 cincin. Jadi struktur dua senyawa ini diprediksi sebagai triaromatik turunan pisena (1) dan tetraaromatik turunan pisena (2).

Adanya senyawa turunan pisena $C_{26}(\mathbf{1})$ dan $C_{25}$ (2) memberikan informasi bahwa sumber bahan organik sampel core berasal dari tumbuhan tingkat tinggi daratan karena memiliki kerangka dasar yang terkait dengan kelompok triterpen oleanan (3) dan ursan (4) (Chaffee dan Fookes, 1988). 
<smiles>CC1(C)CCC2(C)CCC3(C)C(CCC4C5(C)CCCC(C)(C)C5CCC43C)C2C1</smiles>

(3)<smiles>CC1CCC2(C)CCC3(C)C(CCC4C5(C)CCCC(C)(C)C5CCC43C)C2C1C</smiles>

(4)

Senyawa (1) dan (2) terbentuk dari aromatisasi $\beta$-amirin (5) dengan C-3 teroksigenasi mendekati akhir tahap diagenesis ${ }^{5}$ (Chaffee dan John, 1983).

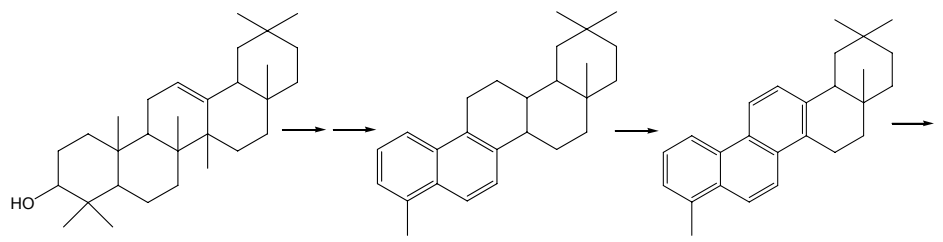

(5)<smiles></smiles>

Gambar 5. Aromatisasi $\beta$-amirin (5) selama tahap diagenesis.

${ }^{5}$ Tahap geologi pertama dengan suhu pemendaman $\leq 50^{\circ} \mathrm{C}$, sampai pada kedalaman $\pm 600 \mathrm{~m}$. Di awal diagenesis sisa-sisa bahan organik makhluk hidup di dalam sedimen akan mengalami proses termal yang akan meningkat dengan bertambahnya kedalaman. Pada kondisi ini senyawa-senyawa organik mulai kehilangan gugus beroksigen akibat reaksi dekarboksilasi dan dehidratasi. Proses defungsionalisasi ini mengarah pada pembentukan hidrokarbon yang lebih stabil seperti hidrokarbon jenuh dan aromatik (Tissot dan Welte, 1978). 


\section{Alkil fenantrena}

Alkil fenantren teridentifikasi pada sampel core melalui fragmentogram $m / z 192$ (Gambar 6) dengan spektrum massa ditunjukkan pada Gambar 7 dan 8.

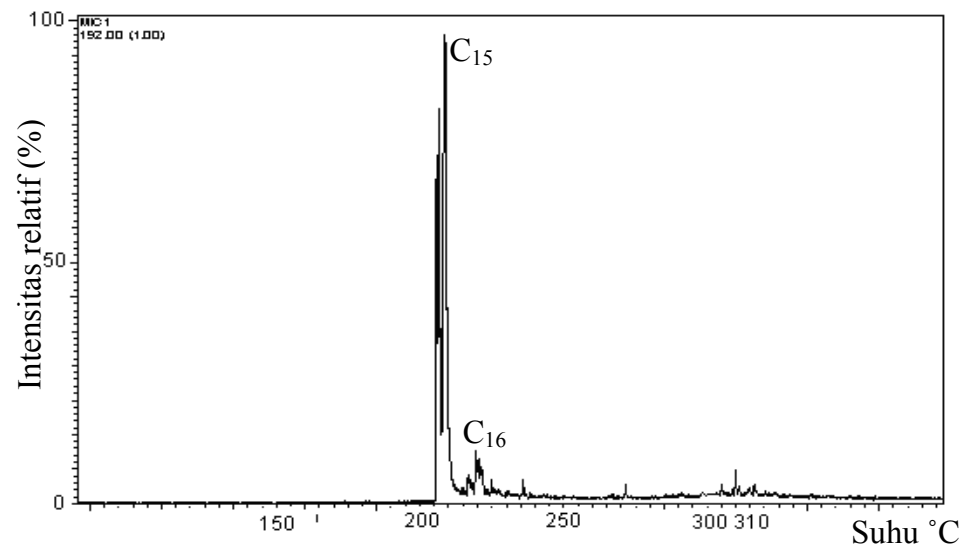

Gambar 6. Fragmentogram m/z 192 fraksi hidrokarbon aromatik sampel core II. Program temperatur oven $100^{\circ} \mathrm{C}$ (5 menit), $100-310^{\circ} \mathrm{C}\left(10^{\circ} \mathrm{C} /\right.$ menit $)$, isotermal $310{ }^{\circ} \mathrm{C}$ selama 10 menit.

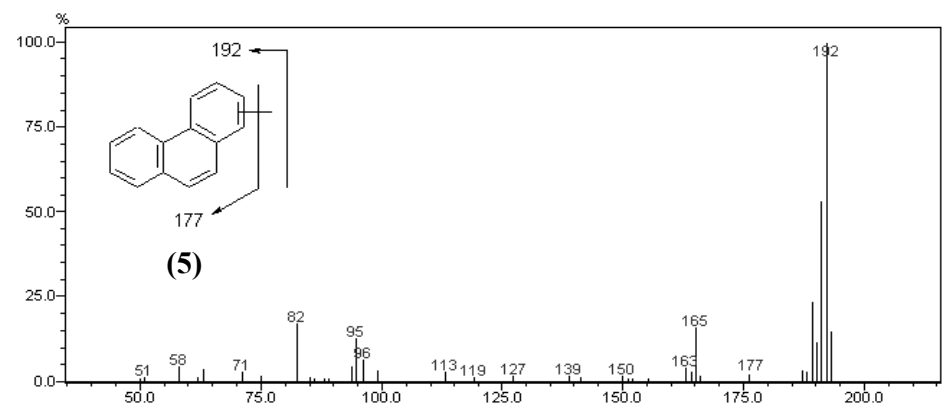

Gambar 7. Spektrum massa puncak ke-1 dari fragmentogram $m / z 192$ 


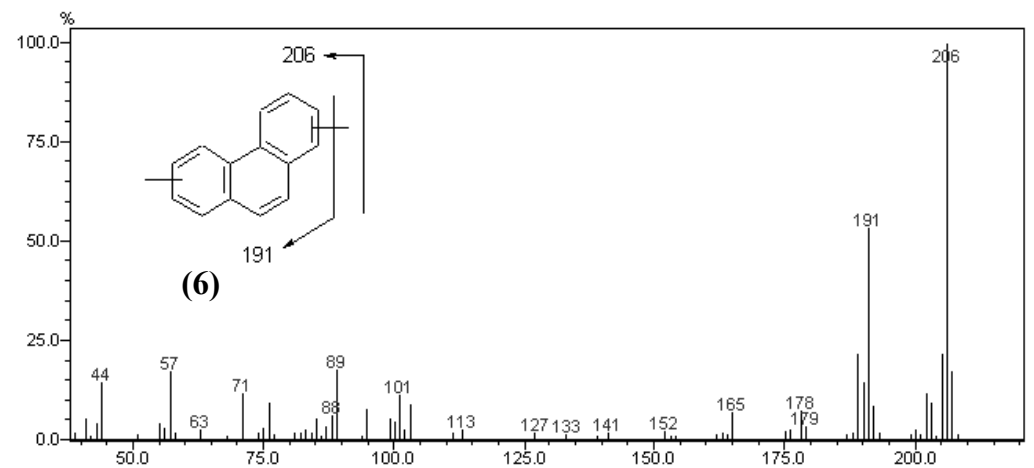

Gambar 8. Spektrum massa puncak ke-2 dari fragmentogram $m / z 192$

Fragmen ion molekuler m/z 192 (Gambar 7) dan m/z 206 (Gambar 8) karakteristik untuk metil fenantren dan dimetil fenantren (Budzinski et al., 1995). Adanya Fragmen ion ini menunjukkan bahwa senyawa yang dimaksud mempunyai derajat ketidakjenuhan 10, terdiri dari 7 ikatan rangkap dan 3 cincin. Jadi senyawa dengan ion molekuler $\mathrm{m} / \mathrm{z} 192$ dan 206 teridentifikasi sebagai metil (5) dan dimetil fenantren (6).

Keberadaan senyawa alkil fenantren, terutama metil fenantren (5) dapat menentukan tingkat kematangan sampel geologi. Namun, pada penelitian ini kematangan sampel core tidak dapat ditentukan secara kuantitatif karena metil fenantren (5) yang ada belum dapat dipastikan isomer yang stabil (2 dan 3-metil fenantren) dan isomer yang kurang stabil (1 dan 9-metil fenantren). Padahal isomer-isomer ini diperlukan dalam menentukan tingkat kematangan sampel core (Killops dan Killops, 1993). Namun secara kualitatif, keberadaan senyawa (5) dan (6) memberikan informasi bahwa sampel core diduga telah matang secara termal karena senyawa (5) dan (6) terbentuk dari triaromatik steroid pada suhu yang tinggi, yaitu tahap katagenesis ${ }^{6}$

6 Tahap geologi kedua yang berlangsung pada kedalaman sekitar $600 \mathrm{~m}$ sampai $3000 \mathrm{~m}$ dengan pemanasan pada temperatur 50 -

78 Jurnal PHENOMENON, Volume 2 Nomor 1, November 2011 
(Philp, 1985). Jadi, adanya alkil fenantren menunjukkan bahwa sampel core diduga telah matang secara termal. Namun, tidak memberikan kontribusi secara kuantitatif terhadap tingkat kematangan sampel.

\section{Triaromatik steroid}

Senyawa triaromatik steroid teridentifikasi pada sampel core melalui fragmentogram $m / z 231$ (Gambar 9) dengan spektrum massa ditunjukkan pada Gambar 10 dan 11.

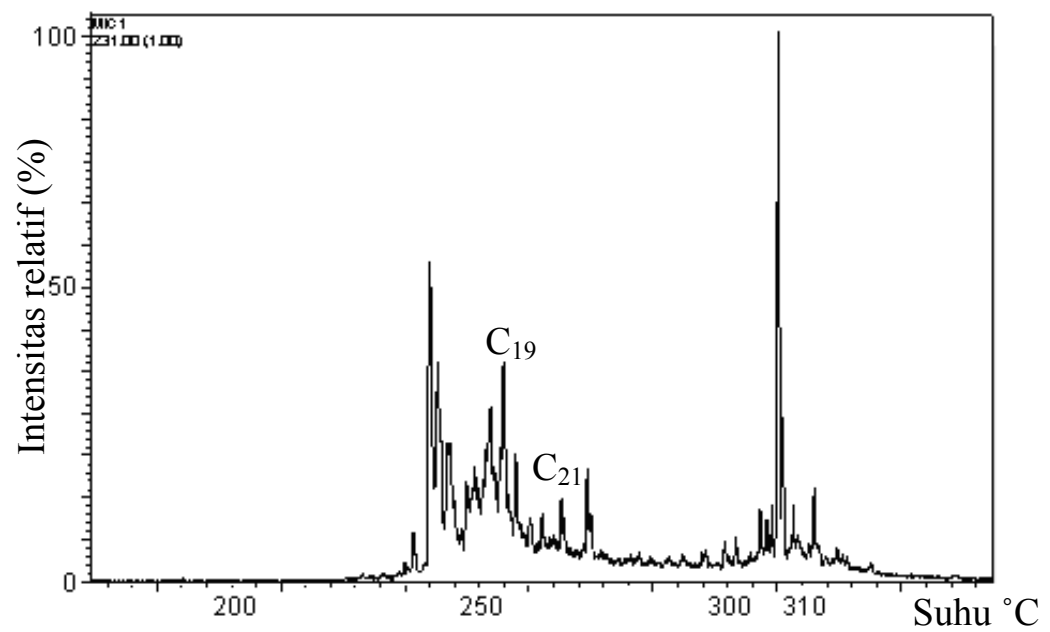

Gambar 9. Fragmentogram $m / z 231$ fraksi hidrokarbon aromatik sampel core II. Program temperatur oven $100^{\circ} \mathrm{C}$ (5 menit), $100-310^{\circ} \mathrm{C}\left(10^{\circ} \mathrm{C} /\right.$ menit $)$, isotermal $310{ }^{\circ} \mathrm{C}$ selama 10 menit.

$150^{\circ} \mathrm{C}$ dibawah kondisi tertentu selama berjuta-juta tahun. Selama proses katagenesis, biomarka mengalami perubahan struktur yang disebabkan karena bertambahnya tekanan dan pemanasan. Pada kondisi ini geopolimer yang terpendam, akibat panas bumi, akan terurai menghasilkan molekul-molekul yang lebih sederhana (Philp, 1986; Peters dan Moldowan, 1993). 


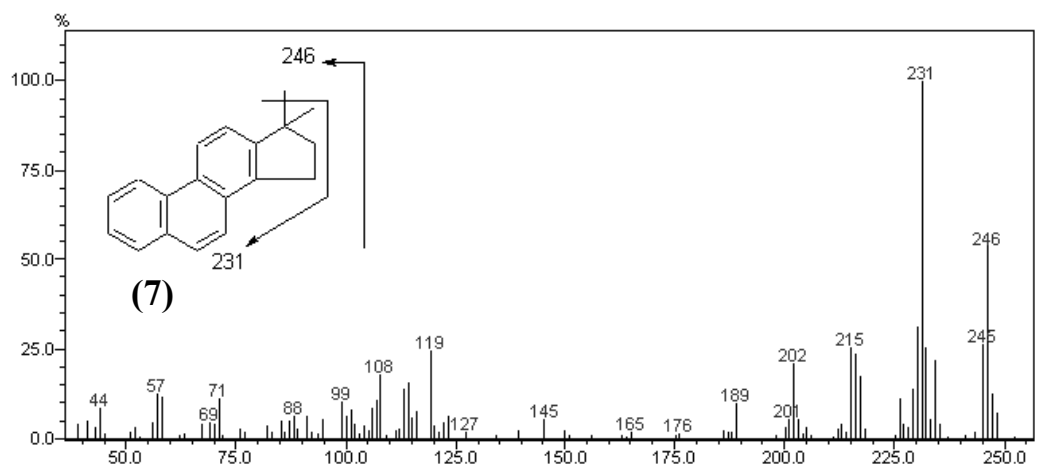

Gambar 10. Spektrum massa puncak ke-4 dari fragmentogram $m / z 231$

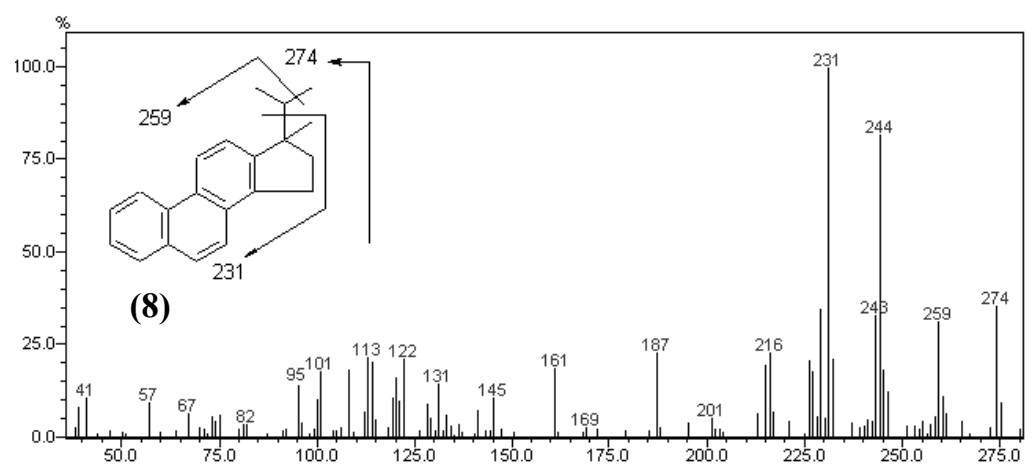

Gambar 11. Spektrum massa puncak ke-5 dari fragmentogram $m / z 231$

Pada Gambar 10, fragmen ion $m / z 231$ (puncak dasar) merupakan fragmen ion khas senyawa triaromatik steroid. Fragmen ion $\mathrm{m} / \mathrm{z} 246$ teridentifikasi sebagai ion molekuler yang berarti senyawa pada puncak ke-4 (Gambar 10) mempunyai derajat ketidakjenuhan 11, terdiri dari 7 ikatan rangkap dan 4 cincin. Jadi, senyawa (7) mempunyai rumus molekul $\mathrm{C}_{19} \mathrm{H}_{18}$. Puncak ke-5 (Gambar 11) dielusidasi analog dengan puncak ke-4, sehingga senyawa (8) mempunyai rumus molekul $\mathrm{C}_{21} \mathrm{H}_{22}$.

Keberadaan senyawa triaromatik steroid (7) dan (8) memberikan informasi bahwa sampel core diduga telah matang 
secara termal karena senyawa triaromatik steroid terbentuk dari aromatisasi monoaromatik steroid pada kisaran suhu $80-120^{\circ} \mathrm{C}$ (Ludwig et al., 1981) yang berarti telah memasuki tahap katagenesis. Hal ini diperkuat dengan fakta terputusnya rantai samping pada senyawa (7) yang menunjukkan bahwa tingginya suhu pemendaman. Fenomena ini tidak mungkin berlangsung pada tahap diagenesis, melainkan pada tahap katagenesis (Beach et al., 1989). Dengan demikian, sampel core diduga telah matang secara termal.

\section{KESIMPULAN DAN SARAN}

Berdasarkan profil dan penjelasan kematangan biomarka fraksi hidrokarbon aromatic dapat disimpulkan bahwa sampel core diduga telah matang secara termal. Namun, dugaan ini yang bersifat kualitatif perlu adanya kajian atau analisis yang mendalam tentang tingkat kematangan materi organik sampel core. Analisis lanjutan tentang kematangan termal terhadap senyawa hidrokarbon dalam sampel minyak yang berasal dari sampel core tersebut. Harapannya dari hasil analisis atau kajian dua sampel (core dan minyak yang dihasilkannya) akan diperoleh kepastian tentang kematangan termal materi organiknya.

\section{UCAPAN TERIMA KASIH}

Penulis mengucapkan terimakasih kepada pimpinan perusahaan VICO Indonesia yang telah memberikan sampel core dan Sudomo (Laboran Laboratorium Kimia Organik Universitas Gadjah Mada) atas bantuan analisa KG-SM. 


\section{DAFTAR KEPUSTAKAAN}

Beach, F., Peakman, T. M., Abbott, G. D., Sleeman, R., dan Maxwell, J. R., (1989), “Laboratory Thermal Alteration of Triaromatic Steroid Hydrocarbons, Organic Geochemistry, 14, 109-111.

Chaffee, A. L., dan Fookes, C. J. R., (1988), “Polycyclic Aromatic Hydrocarbons in Australian Coals-III. Structural Elucidation by Proton Nuclear Magnetic Resonance Spectroscopy', Organic Geochemistry, 12, 261-271.

Chaffee, A. L., dan John, R. B., (1983), "Polycyclic Aromatic Hydrocarbons in Australian Coals-I. Angularly Fused Pentacyclic tri- and tetraaromatic Components of Victorian Brown Coal", Geochimica et Cosmochimica Acta, 47, 2141-2155.

Cole, G. A., Mahdi, A., Abu-Ali., Colling, E. L., Halpern, H. I., Carrigan, W. J., Savage, G. R., scolaro, J., dan AlSharidi, S. H., (1995), "Petroleum Geochemistry of the Midyan and Jaizan Basins of Red Sea, Saudi Arabia", Marine and Petroleum Geology, 12, 597-614.

Killops, S.D., dan Killops, V.J., (1993), “An Introduction to Organic Geochemistry", John Wiley \& Sons, Inc., New York, 77-86 dan 157-159.

Larcher, A. V., Alexander, R., dan Kagi, R. I., (1987), “Changes in Configuration of Extended Moretanes with Increasing Sediment Maturity", Organic Geochemistry, 11, 59-63.

82 Jurnal PHENOMENON, Volume 2 Nomor 1, November 2011 
Ludwig, B., Hussler, G., Wehrung, P., dan Albrecht, P., (1981), ${ }^{\prime} \mathrm{C}_{26}-\mathrm{C}_{29}$ Triaromatic Steroid Derivatives in Sediments and Petroleums. Tetrahedron Letters, 22, 3313-3316.

Mango, F. D., (1991), The Stability of Hydrocarbons under The Time-Temperature Conditions of Petroleum Genesis, Nature, 352, 146-148.

McCarthy, R.D. and Duthie, A.H., (1962), “A Rapid Quantitative Method for The Separation of Free Fatty Acids from Other Lipids", J. Lipid Research, 3, pp. 117-119.

Peters, K.E., dan Moldowan, J.M., (1993), “The Biomarker Guide: Interpreting molecular, fossils in Petroleum, and Ancient Sedimens", Prentice Hall Inc., New Jersey, 4-5.

Philp, R. P., (1986), "Geochemistry in the Search for Oil”, CEEN, 10, 28-43

Tissot, B. and Welte, D., (1984), "Petroleum Formation and Occurrence", $2^{\text {nd }}$ edition, Springer-Verlag, Heidelberg. 